\title{
Pandemia de influenza por el nuevo virus A(H1N1) 2009 en Chile. ¿Cómo hemos vivido esta primera ola?
}

$\mathrm{E}$ sta pandemia de influenza, que esperábamos debutando en Asia y desde las aves, nos enseña que la naturaleza siempre es caprichosa y enigmática.

Desde la alerta por la emergencia de un nuevo virus influenza A(H1N1) a fines de abril del 2009, con la capacidad de producir enfermedad y transmitirse eficientemente entre las personas, la comunidad científica del mundo y de nuestro país ha avanzado en un camino que en su inicio tenía mas incertidumbres que certezas.

En este recorrido, el péndulo de la caracterización de la pandemia, en términos de la severidad, se ha desplazado desde el extremo de grave, por cifras iniciales de mortalidad cercanas al $10 \%$, hasta el extremo de leve, incluso llegándose a plantear que tenía menor morbilidad que la influenza estacional.

A la fecha, y con acumulación de mayor evidencia científica, este péndulo se ha ubicado en una posición más central, quizás más cercana a la realidad. Así, la actual pandemia, ocasionada por el nuevo virus influenza pandémica (H1N1) 2009, es considerada hoy de gravedad moderada. Esta caracterización, que pareciera ser trivial, reviste la más alta importancia, pues de ello depende la mayoría de las decisiones que se tomaron y que aún deben tomarse con respecto al manejo de esta nueva amenaza para la humanidad.

\section{Evidencias para la toma de decisiones}

Desde el comienzo de la epidemia, a fines de abril, afectando a América del Norte hasta la detección de los primeros casos en Chile a mediados del mes de mayo, muchas interrogantes no habían sido resueltas.

Había que considerar que las cifras más cercanas a la evolución natural de la enfermedad, probablemente eran aquellas que provenían del análisis y caracterización de la situación en México, donde la mayoría de los casos no habían sido modulados por el uso de antivirales. La situación en los Estados Unidos era diferente pues el uso importante de antivirales no permitía evaluar claramente la gravedad de la enfermedad, el riesgo de complicaciones $\mathrm{y}$ de muerte.

En nuestro país se sumaba además la incertidumbre del impacto del factor climático. En America del Norte, la epidemia evolucionaba durante la primavera; en cambio para nuestro país, el comportamiento del nuevo virus podría ser diferente dado nuestro periodo invernal, asociándose además la circulación de otros virus respi- ratorios propios de la temporada, incluyendo los virus de influenza estacional.

Así comienza la pandemia en Chile, con muchas incertidumbres pero también con un plan de respuesta previamente preparado lo que permitió activar los sistemas, movilizar recursos, equipos humanos bien preparados, servicios de salud en alerta máxima, sistemas de vigilancia a todo vapor y la existencia de insumos, entre estos un stock estratégico de antivirales que nos permitirían enfrentar, de la mejor manera posible, esta tormenta, esperando atenuar la masiva presentación de casos y disminuyendo los casos graves y muertes.

Desde entonces, hemos vivido dos meses con la circulación del virus de influenza pandémico, y hemos recopilado información relevante que ha permitido la adaptación de las medidas de enfrentamiento de acuerdo a ella.

\section{¿Que hemos aprendido hasta ahora?}

Con el correr de la epidemia en Chile, hemos aprendido en primer lugar que el nuevo virus es altamente transmisible, afectando a un porcentaje importante de la población y alcanzando tasas de incidencias semanales que han superado en mucho las tasas del año históricamente más intenso de circulación de influenza, el 2004. Esto no es de extrañar, dado que la población es susceptible al nuevo virus y que las condiciones climáticas del invierno favorecen su mayor circulación y más eficiente trasmisión.

El comportamiento de la circulación del virus no ha sido igual a lo largo del país, presentando las regiones del norte un inicio más tardío y mucho más abrupto que en las regiones del centro y del sur. Hemos observado también tasas de incidencias distintas, lo que nos lleva a la segunda conclusión, la heterogeneidad de la epidemia, presentando variaciones regionales y sectoriales.

El hecho de tener un número alto de personas que han enfermado o enfermarán implica que, aunque las tasas de enfermedad grave y mortalidad no sean tan elevadas, nos vemos enfrentado a números elevados de hospitalizaciones y de muertes en un periodo corto de tiempo.

La población más afectada en términos de incidencia en esta epidemia ha sido el grupo entre 5 y 19 años de edad. La mayoría de los casos han evolucionado con cuadros leves, sin complicaciones y se han ido configurando poblaciones de riesgo para presentar enfermedad grave que requieren de hospitalización y aquellos que presentan 
mayor riesgo de mortalidad. A los factores de riesgos ya conocidos para influenza estacional como personas con patologías asociadas, especialmente respiratorias y embarazo, se han agregado nuevos grupos de riesgo que le ponen un acento de mayor preocupación a esta pandemia. En estos nuevos grupos de riesgo se incluyen personas con obesidad mórbida y quizás el más preocupante, individuos entre 15 y 50 años, adolescentes y adultos jóvenes sanos que han presentado complicaciones y muerte como consecuencia de la infección. Paradojalmente, las personas sobre 65 años de edad no han sido un grupo de riesgo para esta nueva influenza, presentando incluso las tasas de incidencia y de complicaciones más bajas.

Aprendimos también, que en una pandemia las decisiones para enfrentar la amenaza deben ser tomadas con presteza. Muchas de estas decisiones están basadas en modelamientos matemáticos de la enfermedad, en lo que históricamente sabemos de las pandemias, pero sin lugar a dudas en más incertidumbres que certezas. Sin embargo, la tardanza en la toma de decisiones, en espera de contar con información científica sólida, puede generar impactos negativos tanto en la salud de las personas como también a nivel del país, en términos de paralización de la vida cotidiana y de la actividad económica, con un gran costo económico y social como fue lo sucedido en México.

Una de las tantas estrategias implementadas, y quizás controvertida entre la comunidad médica, fue la recomendación de usar antivirales en los consultantes que cumplieran la definición de caso de enfermedad tipo influenza. Esta medida fue adoptada tomando en consideración que los datos de caracterización inicial de la epidemia mostraban que $50 \%$ de los pacientes con complicaciones y mortalidad correspondían a población joven y sana y que el tiempo entre el inicio de los síntomas y la hospitalización era de 3 días. Esta situación ha sido confirmada con la evolución de la epidemia y se repite en los distintos países. En este escenario, en ausencia de elementos que permitieran y permitan hasta hoy predecir quién va a evolucionar con mayor gravedad dentro de esta población y en conocimiento que la mayor efectividad de los antivirales se logra mientras más precoz sea su uso, se asumió la decisión de recomendar terapia antiviral para estos consultantes. Otros países como Gran Bretaña y Japón han adoptado la misma estrategia chilena.

El impacto de esta medida está siendo evaluado pero podemos adelantar algunos comentarios. La consulta precoz a los servicios de urgencia puede haber tenido un impacto en reducir la morbilidad y probablemente también la mortalidad, no sólo por el efecto directo del antiviral si no por la evaluación médica precoz, ya que de otra forma los casos graves no se habrían detectado oportunamente. Por otro lado, redujo también el temor natural de la población que se enfrenta una nueva enfermedad, al saber que se cuenta con una herramienta terapéutica. Su uso generalizado posiblemente impactó también en las tasas de transmisibilidad acortando el período de excreción viral de los enfermos.

El impacto negativo probablemente está en la gran carga de demanda en la atención de salud, especialmente en los servicios de urgencia. En esta mayor carga también esta asociado el temor, fenómeno también observado en la ciudad de Nueva York. En esta ciudad, al comenzar la indicación de tratamiento con antivirales se redujeron las consultas en forma importante. La aparición de resistencia es otro temor al usar en forma amplia antivirales, dada la alta capacidad de mutar de los virus influenza. Esta condición está siendo vigilada y no se han detectado cepas resistentes hasta la fecha en nuestro país.

Analizando los datos para conocer la gravedad de la epidemia en Chile hemos aprendido que las tasas de hospitalización por influenza han alcanzado, en la semana 28 , cifras de 4,2/100.000 habitantes correspondiendo a un $6,3 \%$ de los casos confirmados y afectando especialmente a lactantes bajo un año de edad, quienes presentan tasas de hospitalización de 30/100.000 hbts. La mediana de edad de los hospitalizados es de 29 años. La mortalidad observada a la fecha corresponde a $0,6 \%$ de los casos confirmados, la mayoría varones, con una mediana de edad de 47 años. Casi 50\% de las muertes corresponde a personas con alguna enfermedad de base y la otra mitad han ocurrido en personas jóvenes y sanas.

El debut de este nuevo virus pandémico prácticamente eliminó la circulación del virus de influenza estacional pero no afectó la circulación de los otros virus respiratorios, en particular del VRS.

Hay aún muchas preguntas, los estudios diseñados y en curso en nuestro país nos permitirán responder sobre tasa de ataque, factores de riesgo, proporción de casos graves y tasas de mortalidad, eficacia del uso precoz de oseltamivir, entre otras.

El tiempo y la evaluación de esta primera ola pandémica, comparando las medidas y su impacto en diferentes países y comunidades, permitirán para una segunda fase, si la debemos enfrentar, tomar decisiones basadas en el conocimiento adquirido y la experiencia.

Jeannette Dabanch P. y Cecilia Perret P. Comité de Expertos Asesor Ministerio de Salud de Chile 